\title{
Acute and chronic antihypertensive effects of Cinnamomum zeylanicum stem bark methanol extract in L-NAME-induced hypertensive rats
}

Paulin Nyadjeu', Elvine Pami Nguelefack-Mbuyo², Albert Donatien Atsamo ${ }^{3}$, Telesphore Benoît Nguelefack², Alain Bertrand Dongmo ${ }^{4^{*}}$ and Albert Kamanyi ${ }^{2}$

\begin{abstract}
Background: Previous study showed that the aqueous extract of the stem bark of Cinnamomum zeylanicum possesses antihypertensive and vasodilatory properties. The present work investigates the acute and chronic antihypertensive effects of the methanol extract of Cinnamomum zeylanicum stem bark (MECZ) in L-NAME-induced hypertensive rats.

Methods: The acute antihypertensive effects of $\operatorname{MECZ}(5,10$ and $20 \mathrm{mg} / \mathrm{kg})$ administered intravenously were evaluated in rats in which acute arterial hypertension has been induced by intravenous administration of L-NAME (20 mg/kg). For chronic antihypertensive effects, animals were treated with L-NAME (40 mg/kg/day) plus the vehicle or L-NAME $(40 \mathrm{mg} / \mathrm{kg} /$ day) in combination with captopril $(20 \mathrm{mg} / \mathrm{kg} /$ day) or MECZ (300 mg/kg/day) and compared with control group receiving only distilled water. All drugs were administered per os and at the end of the experiment that lasted for four consecutive weeks, blood pressure was measured by invasive method and blood samples were collected for the determination of the lipid profile. The heart and aorta were collected, weighed and used for both histological analysis and determination of NO tissue content.

Results: Acute intravenous administration of C. zeylanicum extract $(5,10$ and $20 \mathrm{mg} / \mathrm{kg})$ to L-NAME-induced hypertensive rats provoked a long-lasting decrease in blood pressure. Mean arterial blood pressure decreased by $12.5 \%, 26.6 \%$ and $30.6 \%$ at the doses of 5,10 and $20 \mathrm{mg} / \mathrm{kg}$, respectively. In chronic administration, MECZ and captopril significantly prevented the increase in blood pressure and organs' weights, as well as tissue histological damages and were able to reverse the depletion in NO tissue's concentration. The MECZ also significantly lower the plasma level of triglycerides (38.1\%), total cholesterol (32.1\%) and LDL-cholesterol (75.3\%) while increasing that of HDL-cholesterol (58.4\%) with a significant low atherogenic index (1.4 versus 5.3 for L-NAME group).
\end{abstract}

Conclusion: MECZ possesses antihypertensive and organ protective effects that may result from its ability to increase the production of the endogenous $\mathrm{NO}$ and/or to regulate dyslipidemia.

Keywords: Antihypertensive, Antihyperlipidemic, Cinnamomum zeylanicum, L-NAME-hypertensive rat, NO

\footnotetext{
* Correspondence: alainberd@yahoo.fr

${ }^{4}$ Department of Animal Biology and Physiology, University of Douala,

P.O. Box 24157, Douala, Cameroon

Full list of author information is available at the end of the article
} 


\section{Background}

Essential (or primary) hypertension accounts for approximately $90 \%$ to $95 \%$ of patients diagnosed with hypertension [1] and it is mainly caused by endothelial dysfunction which results from NO deficiency. In fact, it has been found that vascular endothelium of hypertensive patients produces less nitric oxide, a key regulator of cardiovascular system and metabolic homeostasis [2]. It acts as an antiatherogenic agent by inhibiting LDL oxidation, platelets aggregation, vascular smooth muscle proliferation, adhesion molecules expression and adhesion of monocytes to the endothelium $[3,4]$. Moreover, NO is known to be an anti-hypertrophic agent [5]. The inhibition of NO production by L-arginine analogue like $\mathrm{N}^{\omega}$ Nitro-L- arginine methyl-ester (L-NAME) therefore results in arterial hypertension, dyslipidemia and histological damages. L-NAME-induced hypertension is thus a suitable model to study the cardiovascular effects of new active substances.

Despite the large number of antihypertensive drugs and the progresses made in the efficacy and tolerability of these agents, it is acknowledged that less than $25 \%$ of treated individuals achieve target blood pressure (BP) (i.e. $<140 / 90 \mathrm{mmHg}$ ) [6]. Trial outcomes have shown that each agent is associated with relative benefits and drawbacks, often within the context of various patient characteristics such as age, co-morbidities and risk status [7]. The current trend towards lower BP goals suggests that more effective and better tolerated antihypertensive therapies will be needed, of which natural products can be considered as one of the potential sources. Indeed, various plant preparations have been used and claimed to have antihypertensive effects. The antihypertensive effects of some of these plants have been validated and others disproved. One of the plants used for the treatment of hypertension is Cinnamomum zeylanicum (Lauraceae). It is a native of Sri Lanka and south India [8]. Moderately sized tree, up to 2-16 m tall and $60 \mathrm{~cm}$ in diameter at breast height, Cinnamomum zeylanicum is covered with a thick, scabrous bark. The leaves are petiolate, opposite for the most part, coriaceous, obtusely pointed with three nerves; the lateral nerves vanishing as they approach the apex. When mature, the leaves are of a shiny green colour on their upper surface, and lighter colour beneath. The flowers are small, white, and arranged in axillaries and terminal panicles. The fruit is an oval berry, which adheres like the acorn to the receptacle, it's larger than the black currant and when ripe has a bluish-brown surface, diversified with numerous white spots [9]. Traditionally, the stem bark of this plant is utilized in the management of various ailments in many Cameroonian communities. For example, it is used for the treatment of gastrointestinal disorders, typhoid fever, rheumatism and muscular pain. It is also used as an aphrodisiac and in cases of cardiovascular disorders including high blood pressure. Many pharmacological investigations carried out on $C$. zeylanicum demonstrated a number of useful effects including anti-nociceptive and anti-inflammatory [10], antidiabetic [11]. Phytochemical studies of C. zeylanicum revealed the presence of phenolic constituents in the fruits [12]. The analyses of the stem bark revealed the presence of tannin, mucilage, coumarine and essential oil. Cinnamaldehyde and camphor are major compounds present in stem-bark oil of this plant [13]. We previously showed that the aqueous extract of this plant possesses acute antihypertensive and vasorelaxant effects [14].

The present study attempted to evaluate the acute and chronic antihypertensive effects of the methanol extract of the stem bark of C. zeylanicum in L-NAME-induced hypertensive rats.

\section{Methods}

\section{Plant collection and extraction}

Fresh barks of C. zeylanicum were harvested in Njombe, Moungo Division in the Littoral Region of Cameroon in January 2007. The plant material was identified at the National Herbarium in Yaounde, in comparison to the voucher specimen number SRFC/22309. The barks were air-dried and ground to a fine powder. $800 \mathrm{~g}$ of the powder obtained were soaked at room temperature in 3 $\mathrm{l}$ of methanol for $48 \mathrm{~h}$, with occasional shaking. After filtration, the filtrate was concentrated by evaporation at $70^{\circ} \mathrm{C}$ under reduced pressure on a rotary evaporator to afford $45 \mathrm{~g}$ of the methanol extract, corresponding to an extraction yield of $5.6 \%$. This extract was dissolved in DMSO (4\%) for daily used.

The major phytochemical groups were determined using the Lieberman Buchard, ferric chloride, copo of magnesium and Vanillin-sulphuric acid tests. Sterols, polyphenolic compounds, flavonoids, alkaloids and saponins were identified in the extract.

\section{Animals and experimental design}

Male Wistar rats, aged 12-16 weeks and weighing 150 to $250 \mathrm{~g}$ were randomly selected from our colony. They were raised in the animal house of the Faculty of Sciences, University of Dschang, Cameroon. Animals were exposed to daily $12 \mathrm{~h}$ light-dark cycle with free access to a standard animal diet and tap water. The effects of Cinnamomum zeylanicum methanol extract (MECZ) were examined acutely and chronically in vivo on mean arterial blood pressure (MABP) of rats previously treated with L-NAME.

\section{Ethical consideration}

Experimental protocols used in this study were approved by the Laboratory committee (Laboratory of Animal Physiology and Phytopharmacology, Department of Animal 
Biology, University of Dschang - Cameroon) according to the standard ethical guidelines for laboratory animal use and care as described in the European Community guidelines; EEC Directive 86/609/EEC, of the 24th November 1986 [15].

\section{Blood pressure and heart rate measurement}

Blood pressure and cardiac frequency were determined by the invasive method. Brietly, Animals were anaesthetized by intraperitoneal administration of sodium thiopental at the dose of $50 \mathrm{mg} / \mathrm{kg}$ and a catheter was implanted in the femoral vein for drug administration. Another catheter was inserted in the left carotid artery for direct blood pressure measurement. Both catheters were filled with glucose-saline heparinized solution. The catheter inserted in the carotid artery was connected to a blood pressure transducer model Ugo Basile PRC 21k-10 coupled to an Ugo Basile Unirecord model 7050 for blood pressure recording. A stabilisation period of 30 minutes was observed before any recording. Heart frequency was determined by the use of pulse intervals.

\section{Experimental procedure}

For acute antihypertensive study, a solution of L-NAME, an inhibitor of nitric oxide synthase was intravenously injection to normotensive Wistar rats $(20 \mathrm{mg} / \mathrm{kg})$ after the stabilization period at corresponding volume of $100 \mu \mathrm{l} /$ $100 \mathrm{~g}$ bw. MECZ was administered intravenously at the doses of 5,10 or $20 \mathrm{mg} / \mathrm{kg}$, twenty minutes after L-NAME administration, when the rise in blood pressure induced by L-NAME had reached the maximum [16].

In the chronic study, male Wistar rats were randomly divided into four groups of eight rats each. The first group (control) received a solution of DMSO 4\% daily, while the second one (L-NAME group) received L-NAME $(40 \mathrm{mg} / \mathrm{kg} /$ day $)$ plus the vehicle. The third group was treated every day with a combined solution of L-NAME (40 mg/kg/day) and captopril (LN-Capto; $20 \mathrm{mg} / \mathrm{kg} /$ day) while the forth group, received a combination of L-NAME (40 mg/kg/day) and MECZ (LN-MECZ; $300 \mathrm{mg} / \mathrm{kg} /$ day). All the treatments were administered daily by gastric intubation on non-anesthetized animals for 4 weeks at the corresponding volume of $1 \mathrm{ml} / 100 \mathrm{~g}$ bw. The intubation was done daily, on non-anesthetized animals. The dose of the extract was determined based on previous results. At the end of the treatment, animals were anaesthetized by intraperitoneal administration of sodium thiopental $(50 \mathrm{mg} / \mathrm{kg})$ for blood pressure measurement. Immediately after blood pressure measurement, blood samples were collected from the abdominal artery, and centrifuged at $3000 \mathrm{rpm}$ for 15 minutes. The plasma obtained was kept at $-20^{\circ} \mathrm{C}$ for lipid assay. Thereafter, the heart and the thoracic aorta were collected, washed in saline and weighed. The heart was dissected out for the evaluation of the left ventricular mass. Three organs' samples were fixed with $10 \%$ formalin in saline while the five others were used for $\mathrm{NO}$ evaluation.

\section{Biochemical analysis}

The concentrations of total cholesterol (TC), high density lipoprotein (HDL) and triglycerides (TG) in plasma were determined spectrophotometrically using a commercially available kit Dialab and Helios Epsilon spectrophotometer. Low density lipoprotein (LDL) content was calculated from the other lipid parameters according to the [17] equation: $\mathrm{LDL}=\mathrm{TC}-(\mathrm{TG} / 5)-$ HDL. The atherogenic index was calculated using the formula [18]: Atherogenic Index.

The left ventricle and aorta were homogenized in a carbonate buffer solution, and centrifuged at $4000 \mathrm{rpm}$ for 15 minutes. The supernatant obtained was used to measure spectrophotometrically tissue concentration of nitric oxide (NO) as previously described by [19]. Briefly, $300 \mu \mathrm{l}$ of sample were allowed to react with Griess reagent ( $1 \%$ sulfanilamide, $0.1 \%$ N-1naphthylethylenediamine dihydrochloride and $2.5 \%$ phosphoric acid) at room temperature for $10 \mathrm{~min}$, and then the absorbance was read at $530 \mathrm{~nm}$. The NO concentration was determined by using $\mathrm{NaNO}_{2}$ standard curve.

\section{Aortic and left ventricular histological analysis}

Fixed left ventricle and aorta were dehydrated and embedded in paraffin. $5 \mu \mathrm{m}$ thick sections were mounted on glass slides. After deparaffinization and rehydration, they were stained with either Hematoxylin-Eosin or Van Gieson trichrome solutions in order to assess histological injuries and collagen accumulation in tissues. Histological analysis was performed with light microscope. The media thickness of aorta defined as the distance between the internal and external elastic lamina was determined using the following argument. Each photo have a bar corresponding to a given distance $(\mathrm{a} \mu \mathrm{m})$. Knowing that the magnification used was 400 , the length (L) of each bar was then calculated using the formula: $\mathrm{L}=\mathrm{a} \mu \mathrm{m} / 400$.

\section{Drugs used}

L-NAME was obtained from Fluka (Germany), sodium thiopental from Rotex Media (Germany), Heparin from Sanofi (France) and captopril was obtained from the Sahib Singh Agencies (India). All test solutions, including Krebs' solution were freshly prepared in distilled water. 


\section{Statistical analysis}

Statistical analysis was performed using GraphPad Prism version 5.0. All results are expressed as means \pm standard error of the mean. Data were analysed using one-way analysis of variance (ANOVA) followed by Tukeys'post test. Differences between means were considered to be significant when $\mathrm{p}<0.05$.

\section{Results}

Acute antihypertensive effects of the methanol extract of Cinnamomum zeylanicum

Figure 1 shows the acute effects of MECZ on mean arterial blood pressure (MABP) examined in vivo in L-NAME induced hypertensive rats. L-NAME injected intravenously at the dose of $20 \mathrm{mg} / \mathrm{kg}$ in normotensive Wistar rats induced a sustained arterial hypertension which persisted for more than one hour and half with a MABP of $160.33 \pm 3.82 \mathrm{~mm} \mathrm{Hg}$. Immediately following intravenous administration, MECZ induced a significant $(\mathrm{p}<0.001)$ decrease in MABP. The lowest dose $(5 \mathrm{mg} / \mathrm{kg})$ reduced the elevated blood pressure by $46.4 \pm 10.6 \%$. The MABP dropped from $160 \pm 4.02 \mathrm{~mm} \mathrm{Hg}$ to $62.13 \pm$ $11.28 \mathrm{~mm} \mathrm{Hg}$. In animals receiving the doses of 10 and $20 \mathrm{mg} / \mathrm{kg}$, the MABP dropped suddenly after plant administration from $159.46 \pm 5.77 \mathrm{~mm} \mathrm{Hg}$ to $55.46 \pm$ $7.31 \mathrm{~mm} \mathrm{Hg}$ and from $176.66 \pm 6.86 \mathrm{~mm} \mathrm{Hg}$ to $83.46 \pm$ $16.03 \mathrm{~mm} \mathrm{Hg}$; corresponding to an immediate reduction in MABP of $68.9 \pm 4.8 \%$ and $50.7 \pm 9.5 \%$ respectively. The immediate fall in blood pressure induced by previous doses $(5,10$ and $20 \mathrm{mg} / \mathrm{kg}$ ) of the extract was followed by a long-lasting and dose-related antihypertensive effects that lasted for more than one hour with a corresponding decreases of $12.51 \pm 1.7 \%, 27.23 \pm 3.1 \%$ and $30.9 \pm 3.1 \%$, respectively.
Chronic antihypertensive effects of the methanol extract of Cinnamomum zeylanicum

Animals that received only L-NAME (40 mg/kg/day) were hypertensive after four weeks of treatment. Concomitant administration of L-NAME with captopril (LNCapto; $20 \mathrm{mg} / \mathrm{kg} /$ day) or MECZ (LN-MECZ; $300 \mathrm{mg} /$ $\mathrm{kg} /$ day) prevented the installation of hypertension as depicted in Figure 2. MABP value was $135.6 \mathrm{~mm} \mathrm{Hg}$ in L-NAME treated rats versus $104 \pm 6.83 \mathrm{~mm} \mathrm{Hg}$ and $108.26 \pm 3.1 \mathrm{~mm} \mathrm{Hg}$ in the LN-Capto and LN-MECZ groups respectively. However, no significant change in heart rate was observed between experimental groups (Figure 2).

\section{Long-term effects of the methanol extract of Cinnamomum zeylanicum on the final body weight and some organs weight}

In the control group, the relative body weight increased by $122.5 \pm 2.5 \%$ compared to initial value. This parameter was significantly low $(\mathrm{p}<0.01)$ in $\mathrm{L}-$ NAME treated rats where the body weight increased only by $107.9 \pm 4.3 \%$. Contrary to captopril (112 \pm $3.1 \%)$ slightly prevented the body weight loss induced by L-NAME as compared to the control group while the MECZ did not prevent body weight loss, with the relative body weight $(102.1 \pm 4.5 \%)$ significantly low $(\mathrm{p}<0.01)$ compared to that of the control group (Figure 3).

In contrast to the effects observed on the body weight, long-term administration of L-NAME significantly $(\mathrm{p}<0.001)$ increased both aorta $(160.2 \pm 15.3 \mathrm{mg} /$ $100 \mathrm{~g}$ bw versus $58 \pm 4 \mathrm{mg} / 100 \mathrm{~g}$ bw in the control group) and left ventricle $(1.14 \pm 0.11 \mathrm{~g} / 100 \mathrm{~g}$ bw versus $0.68 \pm 0.04 \mathrm{~g} / 100 \mathrm{~g}$ bw in the control group) weights.

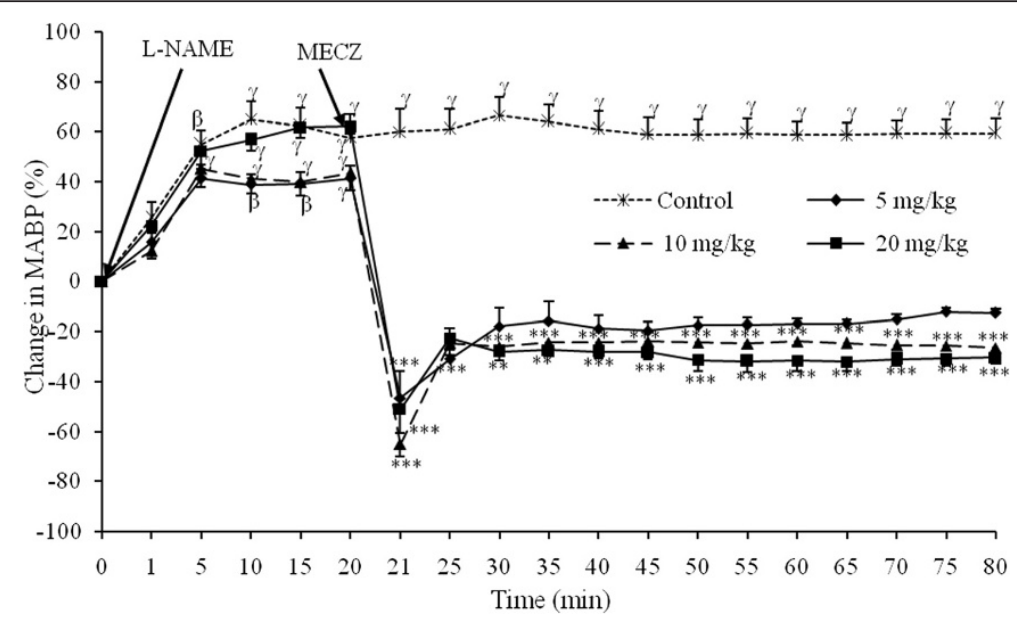

Figure 1 Effect of the methanol extract from Cinnamomum. zeylanicum stem bark on the mean arterial blood pressure in L-NAMEinduced hypertensive rats. Each point represents the mean $\pm \operatorname{SEM}(n=5)$; ${ }^{a} p<0.05,{ }^{\beta} p<0.01$ and ${ }^{\gamma} p<0.001$ significantly different compared to the initial value (0 minute). ${ }^{* *} p<0.01$ and ${ }^{* * *} p<0.001$ significantly different compared to the value 20 minutes after

L-NAME administration. 


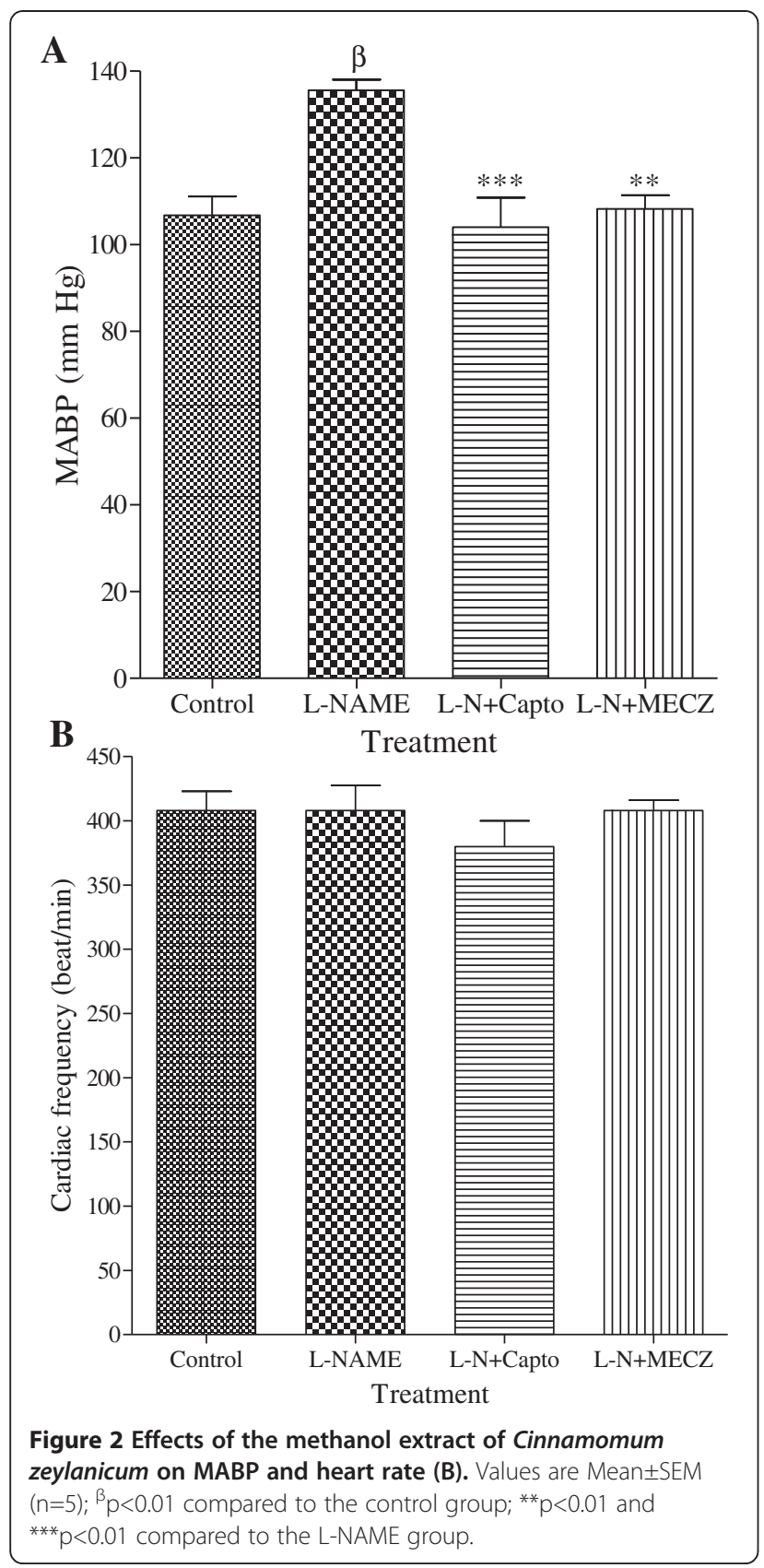

The heart and vascular hypertrophy induced by LNAME administration was significantly $(\mathrm{p}<0.01)$ prevented by captopril and MECZ (Figure 4).

\section{Aortic and left ventricle histomorphologies}

Hematoxylin \& Eosin staining revealed in L-NAME treated rat, an aortic media hypertrophy, characterized by an increase in the vessel section area $(58 \pm 0.11 \mu \mathrm{m}$ versus $43 \pm 0.03 \mu \mathrm{m}$ in the control group). Moreover, cell accumulation on the endothelial wall was also noticed; which could lead to endothelial impairment.

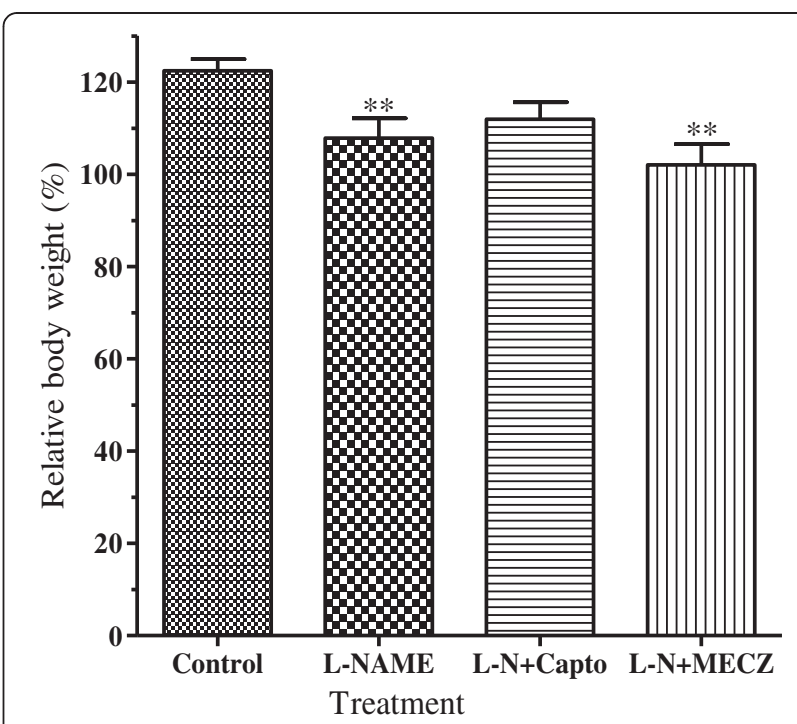

Figure 3 Effects of chronic treatment on the rat relative body weight. $n=5 ;{ }^{* *} p<0.01$ significantly different compared to the control.

These vascular morphological damages were almost completely prevented by captopril $(45 \pm 0.21 \mu \mathrm{m}$ versus $58 \pm 0.11 \mu \mathrm{m}$ in the L-NAME group) as well as the plant extract $(45 \pm 0.4 \mu \mathrm{m}$ versus $58 \pm 0.11 \mu \mathrm{m}$ in the L-NAME group) (Figure 5A). Van Gieson trichrome revealed left ventricular structural changes characterized by fibrosis in L-NAME rats. In rats receiving either captopril or C. zeylanicum extract, the left ventricular histological injury was significantly attenuated (Figure 5B).

Effects of the methanol extract of C. zeylanicum on tissue nitric oxide

Aortic and cardiac content in NO are represented in Figure 6. In rats treated only with L-NAME, both aortic and cardiac NO concentration decrease significantly $(\mathrm{p}<0.01)$ by $39.4 \%$ and $45.2 \%$ respectively as compared to the control. The methanol extract of C. zeylanicum significantly prevented the deleterious effects of LNAME in the tissue NO content. It increased by $47.7 \%$ and $38.4 \%$ the concentration of NO in the aortic and cardiac tissues respectively compared to the L-NAME group.

Effects of the methanol extract from C. zeylanicum on the plasma lipid profile

The oral administration of L-NAME $(40 \mathrm{mg} / \mathrm{kg})$ to rats resulted in an elevated plasma lipid profile (Table 1). LNAME treated rats showed significantly $(\mathrm{p}<0.01)$ higher levels of plasma triglycerides, total cholesterol, LDL-cholesterol and significantly $(\mathrm{p}<0.001)$ lower levels of HDL-cholesterol compared to the normal 

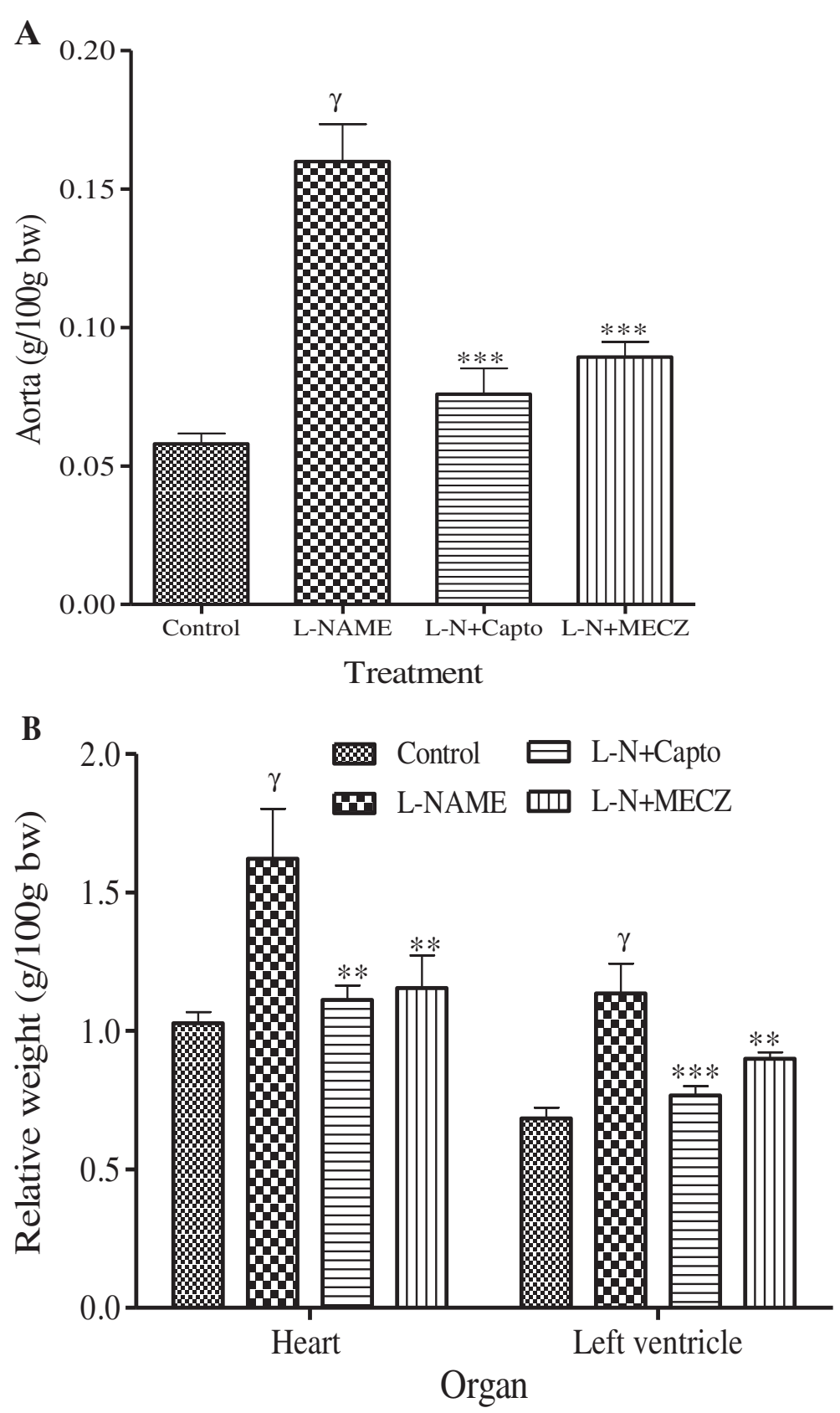

Figure 4 Effects of the chronic treatment on the aorta, heart and left ventricle relative weight. Values are Mean \pm SEM $(n=5) ;{ }^{\gamma} p<0.001$ significantly different compared to the control group; ${ }^{* *} \mathrm{p}<0.01$ and ${ }^{* * *} \mathrm{p}<0.001$ significantly different compared to the L-NAME group.

control rats. The methanol extract of the stem bark of Cinnamomum zeylanicum (300 mg/kg/day) significantly modulated the lipid profile in animals receiving concomitantly L-NAME, reducing triglycerides and total cholesterol by $38.10 \%$ and $32.1 \%$, respectively. The extract increased the level of plasma HDL-cholesterol by $58.4 \%$ while reducing that of LDL-cholesterol by $75.3 \%$, with and atherogenic index closer to that of the control untreated rats.

\section{Discussion}

This study investigated the acute and chronic antihypertensive effects of the stem bark methanol extract of Cinnamomum zeylanicum in L-NAME-induced hypertensive rats and its effects on lipid metabolism in chronic hypertensive rats. In this model, inhibition of NO-synthase permits the evaluation of the nitric oxide pathway, a physiologically important vasodilator, playing a major role in the regulation of systemic 

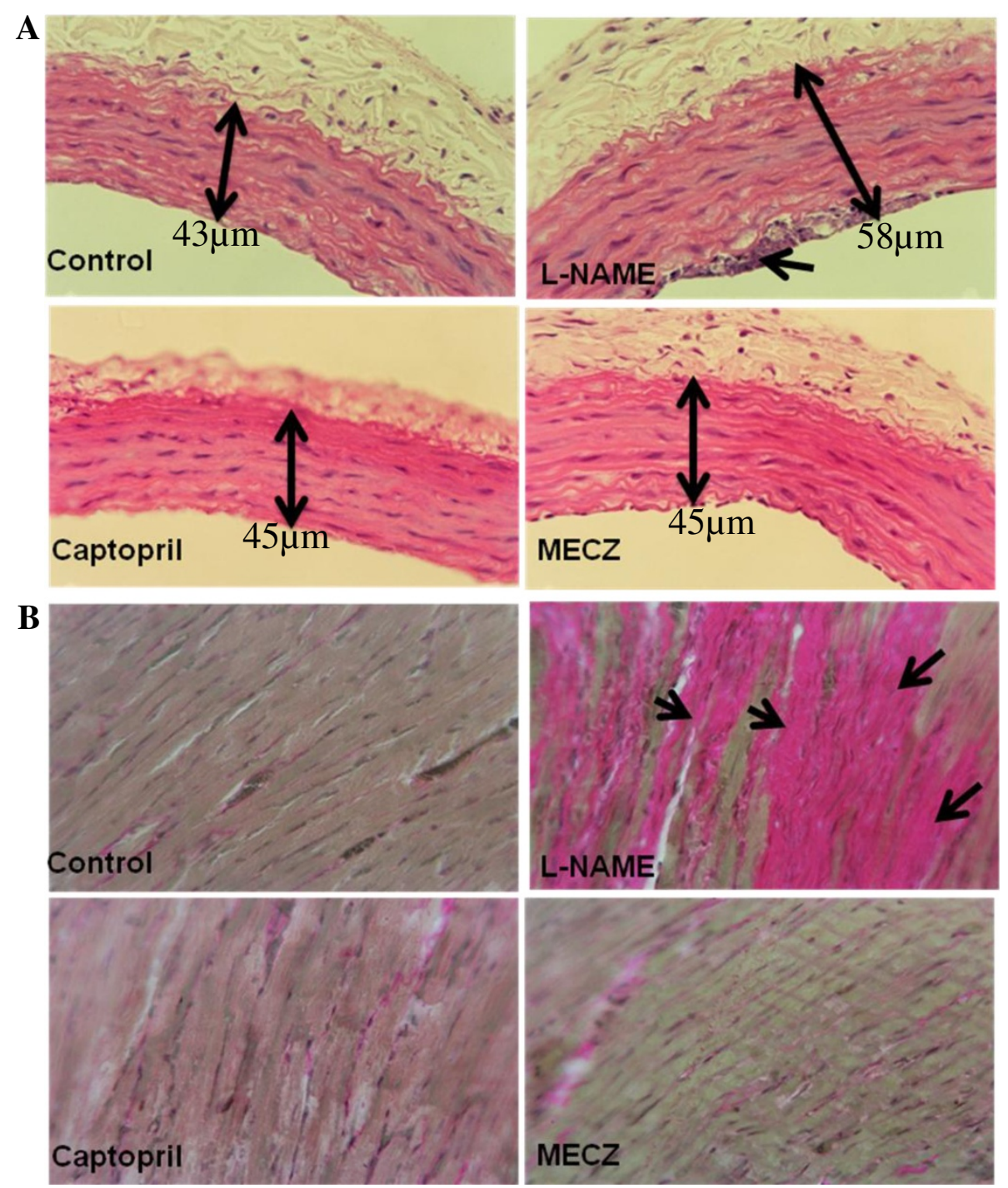

Figure 5 Representative photographs showing aortic and left ventricular histomorphologies respectively stained with Hematoxylin \& Eosin and Van Gieson trichrome. Magnification: 400X.

hemodynamic [20]. Acute intravenous administration of Cinnamomum zeylanicum methanol extract to LNAME-induced hypertensive rats caused a significant decrease in mean arterial blood pressure (MABP) that last more than an hour after administration. In animals treated chronically with L-NAME, arterial hypertension associated with both cardiovascular hypertrophy and histological damages were observed. It is well known that L-NAME, administered either acutely by intravenous route or chronically by the oral induced sustained hypertension [16,21,22]. But Chaswal et al. [23] showed that the acute hypertension provoked by L-NAME administration may not involve the renin angiotensin system which is at least partially responsible for the chronic response. The fact that MECZ could reduce both the acute and chronic hypertension induced by L-NAME indicates that it may use another pathway. Previous studies using the aqueous extract of C. zeylanicum have demonstrated that this plant possesses both endothelium-dependent and -independent vasodilating properties [14]. Therefore, we postulate that the acute antihypertensive effect of our plant extract might be mainly due to its ability to reduce the peripheral resistance via its vasodilating activities even though its effect on the renin-angiotensin system, which plays a pivotal role in the development of chronic L-NAME hypertension, cannot be rule out. It is also well known that in this model of experimental arterial hypertension, the sympathetic system tone and baroreflex to phenylephrine are significantly increased [23]. MECZ could also interfere with this system. Permanent increase in systemic blood pressure often 


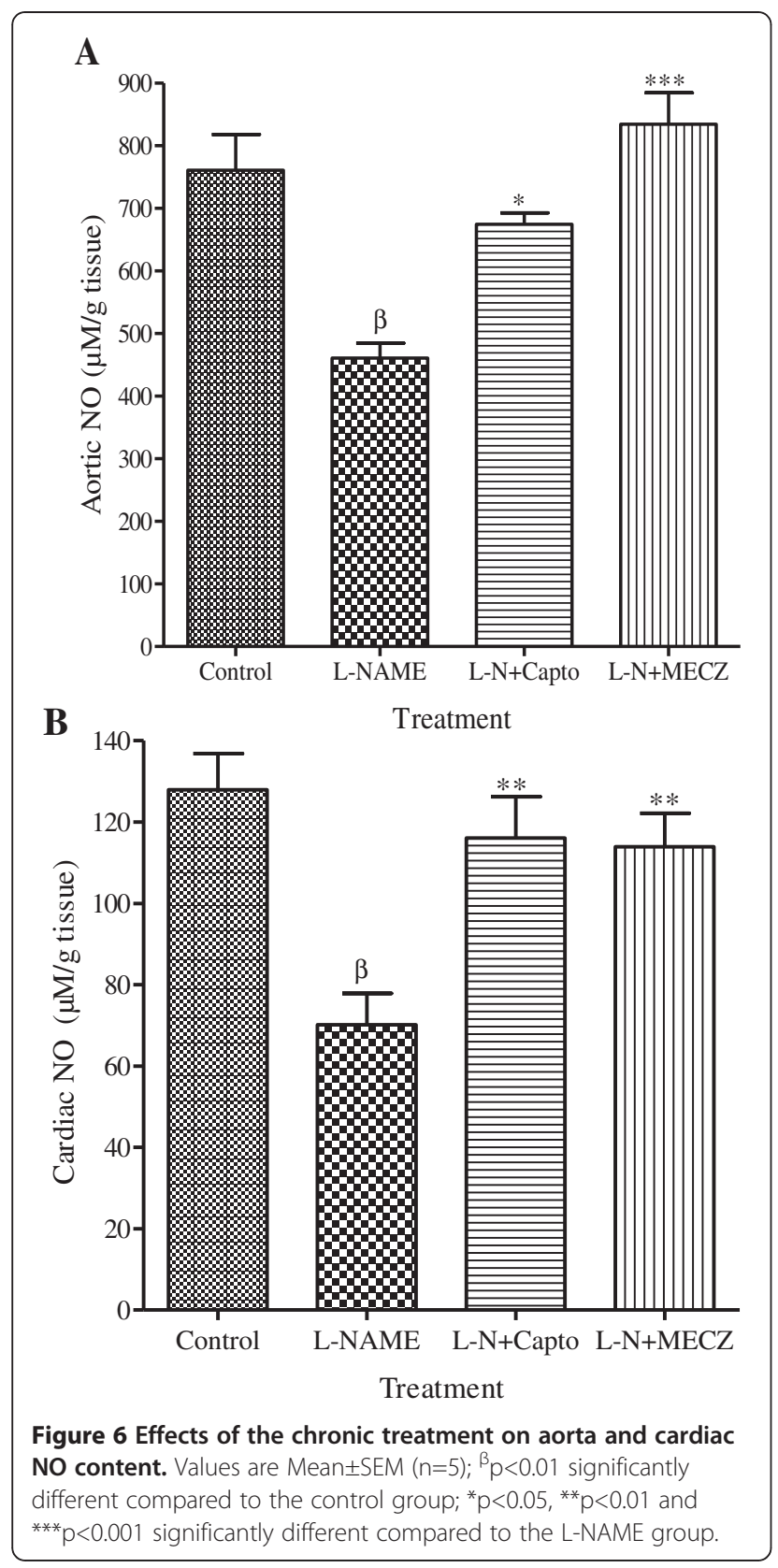

Figure 6 Effects of the chronic treatment on aorta and cardiac NO content. Values are Mean \pm SEM $(n=5) ;{ }^{\beta} p<0.01$ significantly ${ }^{* * *} p<0.001$ significantly different compared to the L-NAME group. lead to cardiovascular hypertrophy [24,25]. In fact, in the present study, it was found that chronic treatment with L-NAME increases the cardiac and aorta weights. Additionally, histological analysis showed the thickness of the vascular wall as well as fibroblast infiltration in the myocardium. These effects were significantly reversed by MECZ and captopril. Results with captopril corroborate many other previous works [26,27] and further confirm the involvement of the reninangiotensin system in the development of this model of arterial hypertension. As there is a tight relationship between the renin-angiotensin system and the sympathetic system, the inhibition of one may lead to the inhibition of the other, as it can be clearly see in the case of captopril. So, no obvious mechanism can be attributed to MECZ. Another interesting fact is that MECZ was able to increase NO production in cardiovascular organs, namely the aorta and the heart. Thus, the antihypertensive as well as the antihypertrophic effects of MECZ may be at least partially attributed to the increase in NO production, which is known as an inhibitor to cell proliferation. Moreover, by stimulating cardiovascular NO synthesis, the plant extract could induces vasorelaxation, improves arterial wall compliance and control of blood pressure. Hypertension and hyperlipidemia are two concomitant cardiovascular risk factors. Therefore, in order to reduce cardiovascular risk, it is important to regulate hypertension as well as dyslipidemia, which is known as a qualitative or quantitative modification of one or several parameters of the plasma lipids [28]. The results of this study indicated a dyslipidemia in rats receiving L-NAME. The dyslipidemia observed was characterized by hypertriglyceridemia, hypercholesterolemia, and high rate of LDL-cholesterol (LDL-C) coupled with low level of HDL-cholesterol (HDL-C. The dyslipidemia observed in L-NAME-induced hypertensive rats, was significantly managed by both the captopril and MECZ with the concentration of triglycerides, total cholesterol, LDL-C or HDL-C, closer to that of normal rats. These results clearly demonstrated both the hypotriglyceridemic and hypocholesterolemic properties of the plant extract, which might contribute to the cardiovascular proptective effects of MECZ. The pharmacological activities of MECZ might be explained by the presence of

Table 1 Effects of the methanol extract from C. zeylanicum on lipid profile in L-NAME hypertensive rats

\begin{tabular}{lccccc}
\hline Treatment & Triglycerides (mg/dl) & Total cholesterol (mg/dl) & HDL-cholesterol (mg/dl) & LDL-cholesterol (mg/dl) & Atherogenic index \\
\hline Control & $53.48 \pm 3.36$ & $50.63 \pm 2.07$ & $48.76 \pm 3.13$ & $5.51 \pm 3.68$ & $1.06 \pm 0.31$ \\
L-NAME & $81.10 \pm 3.80^{\beta}$ & $83.13 \pm 4.02^{\gamma}$ & $17.57 \pm 2.82^{\beta}$ & $38.52 \pm 4.29^{\beta}$ & $5.35 \pm 0.48^{\gamma}$ \\
L-N + Capto & $45.74 \pm 3.36^{* *}$ & $48.12 \pm 2.09^{* * *}$ & $40.40 \pm 3.32^{* *}$ & $4.50 \pm 3.96^{* * *}$ & $1.50 \pm 0.70^{* * *}$ \\
L-N + MECZ & $50.16 \pm 3.33^{*}$ & $56.46 \pm 5.29^{* * *}$ & $42.26 \pm 3.83^{* *}$ & $9.50 \pm 3.08^{* * *}$ & $1.41 \pm 0.18^{* * *}$ \\
\hline
\end{tabular}

$\mathrm{n}=5 ;{ }^{\beta} \mathrm{p}<0.01$ and ${ }^{\gamma} \mathrm{p}<0.001$ significantly different compared to the control; ${ }^{*} \mathrm{p}<0.05,{ }^{* *} \mathrm{p}<0.01$ and ${ }^{* * *} \mathrm{p}<0.001$ significantly different compared to $\mathrm{L}-\mathrm{NAME}$. LNAME group received only L-NAME $40 \mathrm{mg} / \mathrm{kg} /$ day. L-N + Capto received L-NAME plus captopril (20 mg/kg/day) while L-N + MECZ received L-NAME plus extract (300 mg/kg/day). 
phytochemical constituents like flavanoids and saponins in the plant. These bioactive phytomolecules are known to possess vasorelaxant, antihypertensive and antihyperlipidemic effects [29-31].

\section{Conclusion}

In conclusion, this study demonstrated the acute and chronic antihypertensive properties of the methanol extract of Cinnamomum zeylancum stem bark in NOdeficient hypertensive rats. The acute antihypertensive effects might be partially due to the reduction of the peripheral arterial resistance by thwarting the acute inhibitory effect of L-NAME on eNOS. While, the long-term antihypertensive effects could be attributed to the ability of the plant active phytomolecules to inhibit cardiovascular remodelling, to improve arterial wall compliance and to prevent endothelial impairment through its antidyslipidemic effects.

\section{Competing interests}

The authors declare that they have no competing interests.

\section{Authors' contributions \\ PN: Prepared the extract, carried out the assays and drafted the manuscript. EPNM and SLW: Literature search and corrected the manuscript for publication. ADA: Helped in the experimental work. TBN and ABD: Supplied the materials, coordinated the study and refined the manuscript for publication. AK: Supervised the work and refined the manuscript for publication. All authors read and approved the final manuscript for publication.}

\section{Author details \\ ${ }^{1}$ Institute of Fisheries and Aquatic Sciences, University of Douala, P.O. Box 7236, Douala, Cameroon. ${ }^{2}$ Department of Animal Biology, Laboratory of Animal Physiology and Phytopharmacology, University of Dschang, P.O. Box 67, Dschang, Cameroon. ${ }^{3}$ Department of Animal Biology and Physiology, Laboratory of Animal Physiology, University of Yaounde I, P.O. Box 812, Yaounde, Cameroon. ${ }^{4}$ Department of Animal Biology and Physiology, University of Douala, \\ P.O. Box 24157, Douala, Cameroon}

Received: 15 May 2012 Accepted: 28 January 2013

Published: 31 January 2013

\section{References}

1. Beevers G, Lip GY, O'Brien E: ABC of hypertension: the pathophysiology of hypertension. BMJ (Clin Res ed) 2001, 322(7291):912-916.

2. Razny U, Kiec-Wilk B, Wator L, Polus A, Dyduch G, Solnica B, Malecki M, Tomaszewska R, Cooke JP, Dembinska-Kiec A: Increased nitric oxide availability attenuates high fat diet metabolic alterations and gene expression associated with insulin resistance. Cardiovasc Diabetol 2011, 10:68.

3. Alonso D, Radomski MW: The nitric oxide-endothelin-1 connection. Heart Failure Rev 2003, 8:107-115.

4. Anacak GY, Catravas JD: Nitric oxide and the endothelium: history and impact on cardiovascular disease. Vascular Pharmacol 2006, 45:268-276.

5. Garcia J, Dias A, Incerpi EK: Factors and mechanisms involved in left ventricular hypertrophy and the anti-hypertrophic role of nitric oxide. Arq bras de Cardio 2008, 90(6):409-416.

6. Evans RG, Kett MM, Shweta A, et al: New physiological target within the kidney for antihypertensive therapy. Drug Des Rev 2005, 2:167-178.

7. Germino FW: The management and treatment of hypertension. Clin Cornerstone 2009, 9(Suppl 3):S27-S33.

8. Wijesekera RQ: Historical overview of the Cinnamon industry. Rev Food Sci Nat 1978, 10:1-30.
9. Kostermans AJGH: The South Indian species of Cinnamomum Schaeffer (Lauraceae). Bull Bot Surv India 1983, 25:90-133.

10. Atta $A H$, Alkofahi A: Anti-nociceptive and anti-inflammatory effect of some Jordanian medicinal plant extracts. J Ethnopharmacol 1998, 60:117-124.

11. Verspohl EJ, Bauer EJ, Neddermann EK: Antidiabetic effect of cinnamomum cassia and cinnamomum zeylanicum in vivo and in vitro. Phytother Rev 2005, 19:203-206.

12. Jayaprakasha GK, Ohnishi-Kameyama M, Ono H, et al: Phenolic constituents in the fruits of Cinnamomum zeylanicum and their antioxidant activity. J Agric Food Chem 2006, 54:1672-1679.

13. Senanayake UM, Lee TH, Wills RBH: Volatile constituents of cinnamon (Cinnamomum zeylanicum) oils. J Agric Food Chem 1978, 26:822-824.

14. Nyadjeu $P$, Dongmo AB, Nguelefack TB, Kamanyi A: Antihypertensive and vasorelaxant effects of Cinnamomum zeylanicum stem bark aqueous extract in rats. $J$ Compl Integr Med 2011, 8(1):article 2. doi:10.2202/1553-3840.1490.

15. EEC: Council directive $86 / 609 /$ EEC of 24 November 1986 on the approximation of laws, regulations and administrative provisions of the member states regarding the protection of animals used for experimental and other scientific purposes. Offical Journal of the European Communities 1986, L358:1-29.

16. Nguelefack TB, Mekhfi H, Dimo T, Afkir S, Nguelefack-Mbuyo EP, Legssyer A, Ziyyat A: Cardiovascular and anti-platelet aggregation activities of extracts from Solanum torvum (Solanaceae) fruits in rat. J Compl Integr Med 2008, 5(I1):Article 7. doi:10.2202/1553-3840.1105.

17. Friedewald WT, Levy RI, Fredrickson DS: Estimation of the concentration of low-density lipoprotein cholesterol in plasma, without use of the preparative ultracentrifuge. Clin Chem 1972, 18:499-502.

18. Giri RKMK, Sahoo DS, Panda SR, Swain SK, Kanungo VJ, Patro SN, Praharaj J: Lipid lowering activity of the fruit juice of Hippophae rhamnoides $L$. (Seabuckthorn) in hyperlipidemic models of wistar albino rats. Pharmacologyonline 2009, 1:1277-1283.

19. Fiddler RM: Collaborative study of modified method of analysis for nitrite in meat and meat product. J AOAC 1977, 60:594-599.

20. Lerman LO, Chade AR, Sica V, Napoli C: Animal models of hypertension: an overview. J Lab Clin Med 2005, 146:160-173.

21. Chaswal M, Das S, Prasad J, Katyal A, Fahim M: Cardiac autonomic function in acutely nitric oxide deficient hypertensive rats: role of the sympathetic nervous system and oxidative stress. Can J Physiol Pharmacol 2011, 89(12):865-874.

22. Chaswal M, Das S, Prasad J, Katyal A, Mishra AK, Fahim M: Effect of losartan, an angiotensin II type 1 receptor antagonist on cardiac autonomic functions of rats during acute and chronic inhibition of nitric oxide synthesis. Physiol Res 2012, pre-press article.

23. Afkir S, Nguelefack TB, Aziz M, Zoheir J, Cuisinaud G, Bnouham M, Mekhfi H, Legssyer A, Lahlou S, Ziyyat A: Arbutus unedo prevents cardiovascular and morphological alterations in L-NAME-induced hypertensive rats Part I: cardiovascular and renal hemodynamic effects of Arbutus unedo in LNAME-induced hypertensive rats. J Ethnopharmacol 2008, 116(2):288-295.

24. Mulvany MJ: Vascular remodelling of resistance vessels: can we define this? Cardiovasc Res 1999, 41:9-13.

25. Gosse $P$, Jullien $V$, Jarnier $P$, Lemetayer $P$, Clementy J: Hypertrophie ventriculaire gauche au cours de I/hypertension artérielle. Encycl Med Chir (Elsevier, Paris), Cardiologie-Angéiologie 1999, 11(301-1-10):4p.

26. Zicha J, Dobesova Z, Kunes J: Antihypertensive mechanisms of chronic captopril or $\mathrm{N}$-acetylcysteine treatment in L-NAME hypertensive rats. Hypertens Res 2006, 29:1021-1027.

27. Nguelefack-Mbuyo PE, Nguelefack TB, Dongmo AB, Afkir S, Azebaze AGB, Dimo T, Legssyer A, Kamanyi A, Ziyyat A: Anti-hypertensive effect of the methanol/methylene chloride stem bark extract of mammea africana in L-NAME-induced hypertensive rats. J Ethnopharmacol 2008, 117:446-450.

28. Deshmukh M, Lee HW, McFarlane SI, Whaley-Connell A: Antihypertensive medications and their effects on lipid metabolism. Curr Diab Rep 2008, 3:214-220.

29. Dongmo $A B$, Kamanyi A, Franck $U$, Wagner $H$ : Vasodilating properties of extracts from the leaves of Musanga cercrpioides (R. Brown). Phytother Res 2002, 16:56-59. 
30. Han LK, Zheng YN, Xu BJ, Okuda H, Kimura Y: Saponins from platycodi radix ameliorate high fat diet-induced obesity in mice. J Nutr 2002, 132(8):2241-2245.

31. Daniel RS, Devi KS, Augusti KT, SudhakaranNair CR: Mechanism of action of antiatherogenic and related effects of Ficus bengalensis Linn. flavonoids in experimental animals. Indian J Exp Biol 2003, 41(4):296-303.

doi:10.1186/1472-6882-13-27

Cite this article as: Nyadjeu et al: Acute and chronic antihypertensive effects of Cinnamomum zeylanicum stem bark methanol extract in LNAME-induced hypertensive rats. BMC Complementary and Alternative Medicine 2013 13:27.

\section{Submit your next manuscript to BioMed Central and take full advantage of:}

- Convenient online submission

- Thorough peer review

- No space constraints or color figure charges

- Immediate publication on acceptance

- Inclusion in PubMed, CAS, Scopus and Google Scholar

- Research which is freely available for redistribution 